\title{
A Review of the Relationship between Parental Involvement and Secondary School Students' Academic Achievement
}

\author{
Valerie J. Shute, ${ }^{1}$ Eric G. Hansen, ${ }^{2}$ Jody S. Underwood, ${ }^{3}$ and Rim Razzouk ${ }^{1}$ \\ ${ }^{1}$ Department of Educational Psychology and Learning Systems, Florida State University, Tallahassee, FL 32306, USA \\ ${ }^{2}$ Research and Development, Educational Testing Service, Princeton, NJ 08541, USA \\ ${ }^{3}$ Intelligent Automation, Inc., Rockville, MD 20855, USA \\ Correspondence should be addressed to Valerie J. Shute, vshute@fsu.edu
}

Received 24 October 2010; Revised 6 February 2011; Accepted 7 March 2011

Academic Editor: L. Kyriakides

Copyright (C) 2011 Valerie J. Shute et al. This is an open access article distributed under the Creative Commons Attribution License, which permits unrestricted use, distribution, and reproduction in any medium, provided the original work is properly cited.

\begin{abstract}
This paper reviews the research literature on the relationship between parental involvement (PI) and academic achievement, with special focus on the secondary school (middle and high school) level. The results first present how individual PI variables correlate with academic achievement and then move to more complex analyses of multiple variables on the general construct described in the literature. Several PI variables with correlations to academic achievement show promise: (a) communication between children and parents about school activities and plans, (b) parents holding high expectations/aspirations for their children's schooling, and (c) parents employing an authoritative parenting style. We end the results section by discussing the findings in light of the limitations of nonexperimental research and the different effects of children's versus parents' perspectives on academic achievement.
\end{abstract}

\section{Introduction}

An important issue in identifying points of leverage in improving students' academic achievement is determining how and to what degree parental involvement (PI) affects student achievement. Such knowledge might inform parenting practices as well as school-based policies, practices, and interventions that involve working with parents. For example, such research might help in the design and development of interventions that maximize parental involvement, where it has been shown to have the most positive and powerful effect. To assist in this endeavor, we reviewed the literature about the types of PI that might have an impact. We found that the literature on PI is quite "knotty" - complex and sometimes contradictory. This paper attempts to disentangle the knot by closely examining the current literature on the relationship between PI and academic achievement at the middle and high school levels.

The idea that parental involvement engenders students' academic achievement is intuitively appealing to the point that society in general, and educators in particular, have considered PI an important ingredient for the remedy of many ills in education today. In the 1980s and early 1990s, studies were published that suggested the importance of parental involvement in school. In the mid-1990s, the popular press, policy makers, and school administrators actively advocated PI. Legislation was enacted, such as the Goals 2000: Educate America Act and the reauthorized Elementary and Secondary Education Act (ESEA) in the United States, which has made parents' involvement in their children's education a national priority [1]. Schools have been encouraged to reexamine their parental involvement policies and programs and to demonstrate innovative approaches in order to obtain federal education dollars. For example, eligibility for Title I funding is now contingent on the development of agreements where families and schools assume mutual responsibility for children's learning.

Many practitioners and researchers support the policy direction of increased PI in their children's academic lives, yet confusion persists regarding an appropriate definition of PI and the activities, goals, and desired outcomes of various PI programs and policies. Less is known about PI than is commonly assumed. Early studies suggesting the importance of PI are, unfortunately, treated as definitive, regardless of the 
equivocal nature of the data, and they are used to support the position that virtually all types of PI are important. According to Sui-Chu and Willms [2], PI has been treated too long as a one-dimensional construct.

It is apparent that identifying the influence of PI on academic achievement is complicated by at least three factors: (a) researchers use different definitions for the PI construct, (b) there is a paucity of experimental studies in the PI research literature, and (c) mediating factors and interacting variables in the PI-academic achievement story are often ignored. Any effort to clarify the role of PI in academic achievement must consider these issues.

\section{Purpose}

This paper examines the research literature on the relationship between PI and academic achievement, with particular focus on the middle and high school level. Research has shown that in addition to students' personal goals and expectations in this age group, other variables such as PI might exert considerable influence on the students' academic achievement and behavior [3-5].

This paper will examine how PI has been defined, describe the relationships between PI variables and academic achievement, attempt to generalize the results, and finally discuss key areas of controversy and areas for further research.

\section{Methodology}

3.1. Procedure. We began this literature review process by gathering and reviewing many books, reviews, metaanalyses, and individual articles relating to the PI literature. The following online databases were employed to search and collect these sources.

ERIC. A database that provides extensive access to educational-related literature from two printed journals: Resources in Education (RIE) and Current Index to Journals in Education (CIJE).

PsychInfo. An online version of Psychological Abstracts that covers journal articles, book chapters, books, technical reports, and dissertations in psychology and psychological aspects of related disciplines.

EBSCOhost. An online system that provides access to several periodical indexes or databases. These databases contain citations, abstracts and many full-text articles from magazines, journals, and newspapers.

In addition to these databases, Google Scholar, the Brigham Library at Educational Testing Service, and the Strozier Library at the Florida State University were used to search for and acquire specific references. Google Scholar is a web site providing peer-reviewed papers, books, abstracts, and articles from academic publishers, professional societies, universities, and other scholarly organizations. The Brigham Library at Educational Testing Service and the Strozier Li- brary at Florida State University both house comprehensive collections of educational, psychological, sociological, and testing literature.

3.2. Inclusion Criteria. The focus of the search was to access full-text documents using various search terms and keywords such as parental involvement, parental influence, peer influence, personality, academic achievement, and parental involvement. The search was not limited to a particular date range. From the large set of documents that we collected, a total of 74 documents met the criteria for inclusion in the literature review. The inclusion criteria consisted of topical relevance, focus on secondary education, and papers that presented results in terms of prominent PI variables. Additional inclusion criteria were papers that studied any mediating factors and interacting variables in the PI-student academic achievement relationship.

The majority of the documents we obtained were fifty individual studies reported in journal articles, book chapters, and research reports, followed by eight books, six longitudinal studies, five NELS:88 (i.e., the National Education Longitudinal Study of 1988, Institute of Education Sciences, n.d. [6]) reports, three extensive literature reviews, and two meta-analyses. We omitted qualitative studies and studies that did not meet the specified criteria.

3.3. Defining Parental Involvement. Figure 1 depicts the prominent aspects of PI found in the literature. We have grouped these variables into the two main categories of home and school activities.

Many studies examine underlying aspects of PI, yet few do it in exactly the same way [1]. Such differences make it difficult to assess cumulative knowledge across studies and can also lead to contradictory findings. We will point these out in the results section as they arise.

\section{Literature Review Results}

The results of the literature review are presented in terms of how PI variables impact student academic achievement, in two sections: (a) findings around single PI variables and (b) findings of large-scale studies that analyze the PI construct in terms of a set of underlying variables. Then, we discuss the findings in light of the limitations of nonexperimental research and the different effects of children's and parents' perspectives on academic achievement.

4.1. Single Parental Involvement Variables. In this section, we look at the results of different studies on prominent PI variables, including parent-child discussions about school, parental aspirations and expectations, parenting style, reading at home, checking homework, school involvement, and home rules and supervision.

4.2. Parent-Child Discussions about School. The parent-child discussion variable refers to ongoing conversations between parents and their children concerning school-related activities, programs, near- and long-term school plans, and other 


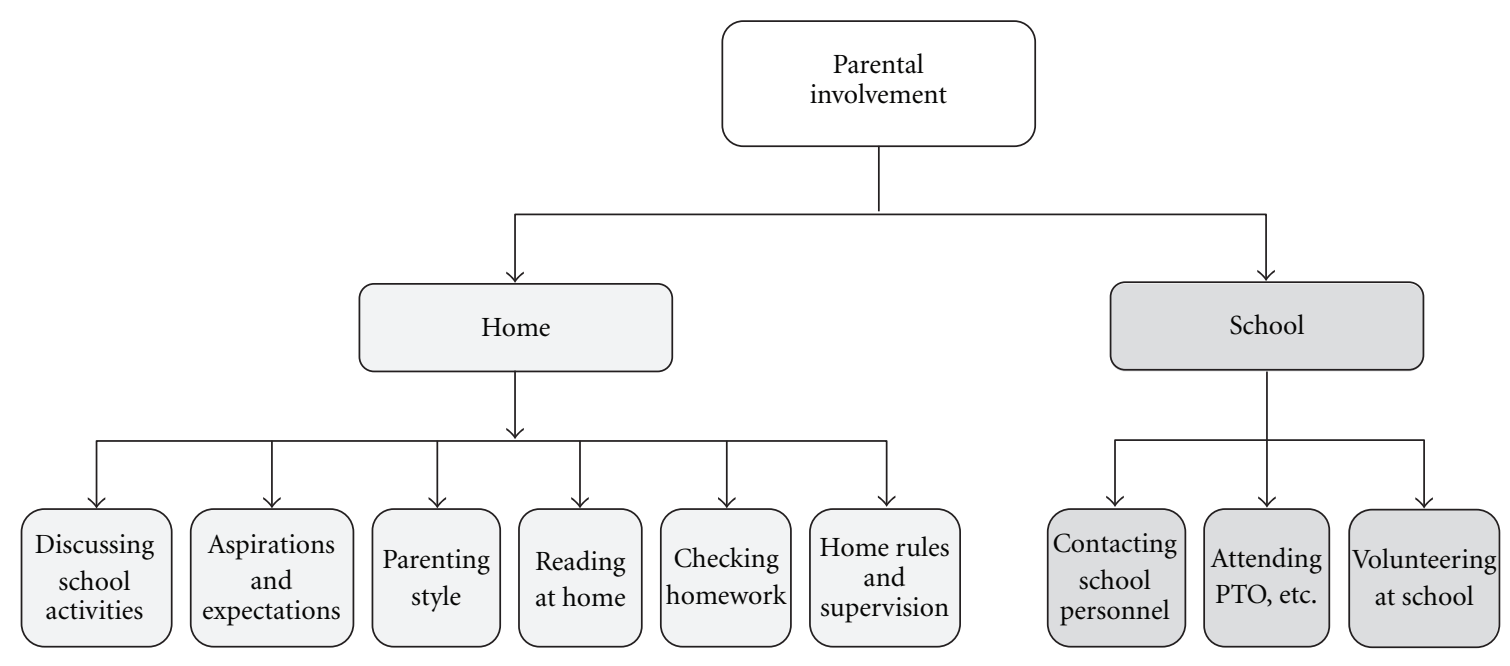

Figure 1: Prominent aspects of parental involvement enacted at home and at school.

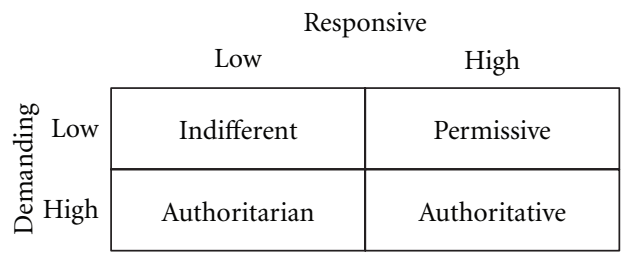

FIGURE 2: A cross of responsive and demanding parenting, yielding four distinct styles.

academic issues. This variable frequently yields the strongest positive association with academic achievement $[2,4,7-11]$. McNeal [4], for example, found that the only dimension of parental involvement that was associated with improved achievement and reduced problematic behavior (e.g., truancy) was parent-child discussion. Parent-child discussion has a significant relationship to student achievement $(\beta=$ $.15, P<.01)$ and a significant inverse relationship to truancy $(\beta=-.08, P<.01)$.

One interesting subtlety involving this variable is that talking with one's mother is positively associated with academic achievement, but the association between talking with one's father and academic achievement may depend on ethnicity and also on whether the child or parent is reporting $[9,12,13]$. For instance, talking with one's father shows no correlation to academic achievement when data are collapsed across ethnicities, but talking with fathers for Black and Hispanic children is negatively related to achievement, while for Asian children talking with fathers is positively related to achievement.

4.3. Parental Aspirations and Expectations. Parental aspirations and expectations are often described collectively or used interchangeably in the literature. Taken together, aspirations and expectations reflect the degree to which parents presume that their child will perform well in school, now and in the future. This variable appears in many PI re- search studies and is generally shown to have a positive relationship to academic achievement. For example, parental aspirations/expectations is the strongest dimension in the Fan and Chen [14] meta-analysis examining effects on academic achievement (overall $r=.40$ ), as well as the strongest predictor $(\beta=.28)$ in the Singh et al. [15]) structural equation modeling study. Parental expectations also has the largest effect size $(d=.88)$ and is one of the strongest predictors in determining academic achievement $(P<.001)$ in Jeynes' $[10]$ meta-analysis on PI variables.

To date, of the PI papers we reviewed, the articles and large-scale studies that focus on parental expectations report a generally positive effect on student achievement. More specifically, Baker and Soden [1] note that high aspirations/expectations, coupled with an effective parenting style (i.e., moderate levels of parental support and supervision) are positively related to academic achievement. Similarly, Kurdek et al. [16] examined the relationship between parental supervision (measured via student report) and sixthgrade students' academic achievement. Their results showed a clear quadratic relationship (i.e., inverted $U$ function) between these two variables, where the highest levels of achievement (measured by grade point average) were associated with moderate levels of parental supervision, while worse achievement related to both low and high levels of supervision respectively. We now turn our attention to research involving parenting style.

4.4. Parenting Style. This PI variable is defined as a complex set of behaviors and/or attitudes by which parents demonstrate and communicate the values, behaviors, and standards that their children are expected to adopt. According to various researchers $[10,17-20]$, parenting style may be viewed along two dimensions: responsive and demanding (see Figure 2).

An authoritative parenting style is consistently and positively associated with student academic outcomes. This style is characterized by parents who are both responsive and demanding (lower right-hand corner of Figure 2). However, 
authoritarian and permissive styles (as well as indifferent styles) are negatively related to academic achievement [18, 21-24].

We examined 28 articles that studied parenting style in some form or another and its relationship to academic achievement. Representative characteristics of parenting style in the literature include authoritative style, joint decision making, PI in children's lives, behavioral supervision, discussion of education with one's children, firm disciplinary practices, permissive (or indifferent) styles, limit setting, strong communication, and maternal and paternal styles. The following are mixed findings in the literature on the variable of parenting style.

4.5. Positive Association. Authoritative parenting style is characterized by parents who develop and maintain close, warm relationships with their children while at the same time establishing structure and guidelines that are enforced as necessary. This parenting style was referred to in seven articles. They all reported a positive association with student achievement [25-30], except for one study that showed no effect for first generation Chinese Americans [31]. Aunola et al. [26] similarly investigated the extent to which adolescents' achievement is associated with parenting styles in their families. They found that adolescents from authoritative families showed significantly greater achievement compared to other adolescents who experienced different parenting styles $(P<.001)$.

In some studies, parental affective support appeared to be one of the strongest predictors of students' academic achievement. For example, in a study by Deslandes et al. [27], they reported that parental affective support was a strong predictor of school achievement for both males $(\beta=.29$, $P<.0001)$ and females $(\beta=.37, P<.0001)$. A child's perception of parenting style was referred to in one article, which reported that child perceptions of parenting style, involvement, and teacher/school communication factors strongly predicted school achievement $(r=.36, P<.001)$ [30]. The recent meta-analysis conducted by Jeynes [10] showed a strong positive association $(P<.001)$ between parental style_-defined as supportive, loving, helpful, and maintaining an adequate level of discipline-and academic achievement.

These positive associations may be due to the ability of parents with an authoritative parenting style to be loving and supportive and yet maintain an adequate level of discipline in the household. Parents with this parenting style also demonstrate qualities such as trust and approachability that motivate children to discuss academic problems and expectations with their parents. Additionally, such parents are more likely to make contact with teachers when students have academic or behavioral problems [10,27].

4.6. No Association or Negative Association. PI in the form of behavioral supervision has shown either no association or a negative relationship with academic achievement [7]. For example, firm disciplinary practices were found to be unrelated to a child's academic success [32], based on a sample of 59 6-11-year-old African Americans from homeless families. A survey with Korean American adolescents showed that differences in parenting styles did not significantly relate to adolescents' academic achievement [33]. And McNeal [4] showed that PI in the form of supervision generally explained behavioral outcomes (e.g., truancy) $(\beta=-.11, P<.01)$ but not cognitive outcomes (e.g., science achievement), and had greater effects for more affluent White students $(\beta=-.13$, $P<.01)$ than for less-advantaged students of any other race. This finding may be the result of minority parents feeling less comfortable getting involved in school-based activities and also being less likely to initiate meetings with school teachers when their child is facing an academic problem. Past negative experiences shape parents' involvement with educational institutions [4].

On the other hand, Deslandes et al. [28] and Chen [8] found a negative relationship between parental supervision and children's achievement. This negative association might be related to the fact that some parents increase their support/supervision when they become concerned with their children's underachievement. In other words, parents adopt strategies based on their children's academic performance $[4,8]$.

4.7. Other PI Variables. Fairly consistent associations between other PI variables and academic achievement include the following.

(i) School involvement, which refers to participation in parent-teacher organizations (PTOs) or associations (PTAs), community involvement, volunteer work, and so on, has shown a positive association with academic achievement $[11,25]$. For instance, Adeyemo [25] examined the effects of different parental involvement dimensions on academic achievement for 250 secondary school students and found that parental involvement in their child's school environment significantly affected students' academic achievement $(\beta=.29, P<.05)$.

(ii) Parent-teacher communication, described as parents' communication with teachers regarding their child's progress, has shown a positive association with students' academic achievement $(\beta=.32, P<.05)$ [10].

(iii) Parents checking child's homework, has shown a positive association with academic achievement in some studies [10, 11]. For instance, Keith et al. [11] found that students whose parents were involved in checking their homework showed higher achievement $(\beta=$ .78) than students whose parents were not involved in checking homework. Other studies, however, have shown a negative association between parents checking their children's homework and academic achievement [34].

(iv) Home supervision and rules, refers to moderate levels of parental support $[10,16]$, and when combined with appropriate monitoring of home-related 
behaviors (such as television viewing) has shown positive associations with academic achievement [11, 35]. Children of parents who closely monitor their activities spend less time watching television and more time on school-related activities, which in turn shows a positive relationship with academic achievement $(\beta=.19)[11]$.

(v) Reading at home, which reflects parental modeling and support of the child's reading along with the provision of a stimulating literacy environment, has shown a positive association with academic achievement $[3,11,25,36]$. For example, in a study by Chen [3], the effect size $(d=.76)$ suggested a strong relationship between parental involvement in their child's reading at home and academic achievement $(P<.001)$.

To summarize, there is seldom more than a small-tomoderate association between any individual PI variable and academic achievement. The strongest associations appear to be (a) discussions about school activities between parent and child (positive), (b) parents' aspirations/expectations for their children (positive), and (c) parental styles, particularly authoritative style (positive) and authoritarian and permissive styles (negative).

While each of the PI variables presented in this section has shown some relationship to students' academic achievement, it is also clear from recent research that the effects are complex. For instance, studies have found interactions between some of these PI variables and academic engagement/involvement (e.g., time spent on homework and paying attention in class), ethnicity, race, family structure, family characteristics (such as parents' education), maternal employment status, socioeconomic status, and gender [9$11,13,27,37-40]$. Consequently, we can view these as potentially moderating or mediating variables in relation to student achievement. For example, in a longitudinal study conducted by Dearing et al. [13] involving 167 children, the effect of PI on the children's academic achievement (i.e., reading) was moderated by maternal education. We now explore more complex analyses of the PI construct.

4.8. Large-Scale Analyses of the PI Construct. In this section, we describe six large-scale studies that have been conducted in the area of PI and academic achievement: (1) Fan and Chen [14], (2) Jeynes [10], (3) Desimone [9], (4) Keith et al. [11], (5) Chen [8], and (6) Sui-Chu and Willms [2]. Each of these studies looks at how a set of underlying variables may illuminate the relationship between overall PI and student academic achievement.

The first study is a meta-analysis conducted by Fan and Chen [14]. The sample consisted of 133,577 students in 25 different studies, yielding 92 correlation coefficients. The method they used was to calculate average correlations between PI (overall construct as well as specific dimensions) and academic achievement. PI dimensions included educational aspirations/expectations for children, communication with children about school-related matters, parental su- pervision and home structure related to school matters, parental participation in school activities, and other/general PI activities.

The result from their analysis regarding the correlation of overall PI to academic achievement is $r=.25$. Based on Cohen's [41] guidelines about the magnitude of correlation as an effect-size measure, a correlation of .25 is a "medium" effect size. The largest correlation was between parents' aspirations and expectations for children's educational achievement (average $r$ about .40), and the smallest correlation involved the variable parents' supervision of the child at home (e.g., rules for watching TV and doing school work), with an average $r=.09$.

Similarly, our second large-scale study reported by Jeynes [10] found a positive relationship between PI and academic achievement. In his meta-analysis, Jeynes included 52 studies that involved more than 300,000 participants. Jeynes aimed to determine the influence of PI on the educational outcomes of urban secondary school children. For this study, PI was defined as parental participation in the educational processes and experiences of their children. The specific PI variables included parental expectations, parent-child communication about school activities, parents checking homework before submission, and parental style (i.e., helpful and supportive parental approach).

Results revealed that the general PI variable yielded statistically significant outcomes of .50 to .55 of a standard deviation unit. The Hedges' $g$ measure of effect size was reported. Like the findings from the Fan and Chen [14] meta-analysis, this index indicated that for overall academic achievement, the effect size for parental expectations was the largest among all of the other variables (Hedges's $g=.88$, which represents a large effect size). The remaining variables (i.e., parent-child communication, parents checking homework, and parental style) showed medium effect sizes (Hedges' $g=.32, .38$, and .40 , resp.).

Desimone [9] conducted a regression analysis examining 12 PI variables on one achievement variable (scores on a standardized test of mathematics) for a large sample $(N=$ $19,386)$ of 8 th graders in the NELS: 88 data. The adjusted $R^{2}$ for this regression is .29, which corresponds to an $r$-value of .54 for overall PI as considered by the set of individual variables. This falls in Cohen's range of large effect sizes.

The regression results of the same 12 variables on two other achievement variables-scores on a standardized test of reading, and an average of self-reported grades in English, mathematics, science, and social studies-were similar to those reported for mathematics. These other regressions showed $R^{2}$ values of .26 and .22 , respectively.

Among the 12 variables predicting mathematics outcome, the strongest predictors of achievement include (a) students reporting that they talk with their parents about school (positive relationship), (b) parents reporting contact with the school (negative relationship), and (c) students reporting that parents check their homework regularly (negative relationship).

One interesting finding from the study concerns whether the student or the parent was reporting on rules in the home (rules on homework, GPA, chores, TV, friends, etc.). That 


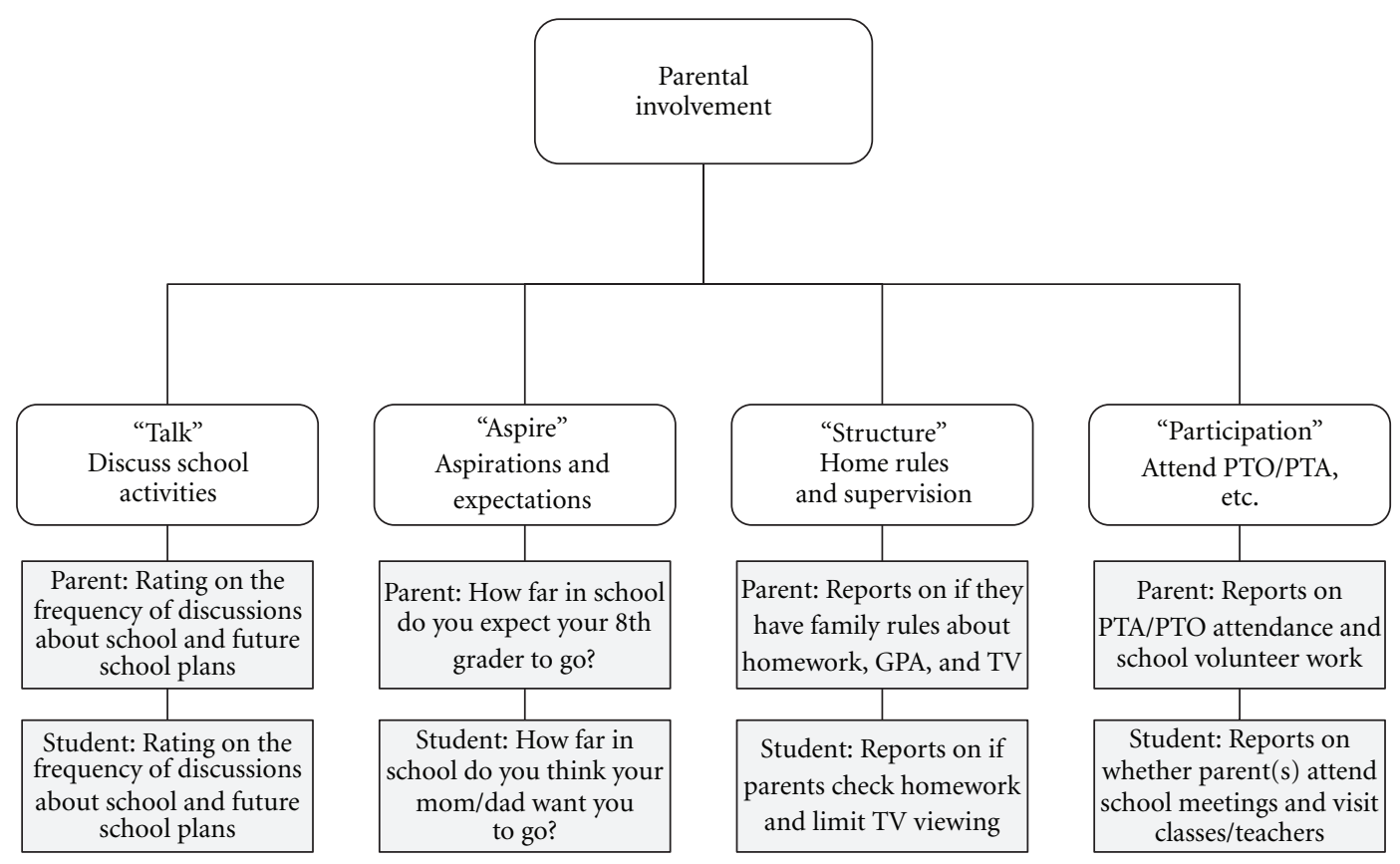

Figure 3: Original four variables underlying the PI construct in the Keith et al. [11] study. Note: adapted from "Does parental involvement affect eighth-grade student achievement? Structural analysis of national data," by T. Z. Keith, P. B. Keith, G. C. Troutman, P. G. Bickley, P. S. Trivette, and K. Singh, 1993, School Psychology Review, 22(3), pp. 483, 486.

is, if the child perceives that parents have rules about doing chores, watching television, and going out with friends, there is a positive relationship to achievement. However, if the parent reports having rules in the home-such as maintaining grade average, doing homework, and being responsible for certain household chores - there is a negative relationship on math achievement. Similarly, there is an opposite relationship involving the variable talking about school. From the students' report, this represents a positive relationship to math achievement, but from the parents' report, this represents a negative relationship.

Desimone [9] further examined the data in terms of ethnicity and reported some interesting patterns of predictor variables. For example, the variable talk with father about school showed a positive relationship to math achievement for Asian children, a negative relationship for Black and Hispanic students, and no significant relationship for White students. The variable rules on homework, chores, $T V$, and so forth was positively related to math achievement if reported by Asian children and negatively associated with math achievement if reported by White parents. Finally, the variable parents check homework from the students' perspective has a significant negative association with achievement across all ethnicities.

A fourth large-scale study that reported a positive relationship between PI and academic achievement was conducted by Keith et al. [11]. This widely cited structural analysis study attempts to establish causal relationships using a sample of about 22,000 8th grade students. This study uses the technique of structural equation modeling (SEM), which entails defining a causal model to which the data are fitted.

Some of the variables that were shown to best fit the causal model relating PI and student achievement included (a) talking about school, (b) aspirations/expectations, (c) structure in the home in the form of rules, and (d) participation in school activities such as PTO. Figure 3 shows these four variables and example topics from the NELS: 88 survey.

Results showed that these four variables are not significantly correlated to one another, and thus PI is multidimensional. In fact, when the structure and participation variables were removed and other variables added (e.g., family background, previous achievement, and ethnicity), as shown in the model depicted in Figure 4, the model fit better.

The student achievement variable (on the right of Figure 4) was derived from scores from short standardized tests of reading, math, science, and social studies (history, citizenship, and geography), developed for NELS by Educational Testing Service (ETS). The largest predictor of student achievement is, not surprisingly, students' previous achievement. However, Keith et al. [11] also found unique variance attributed to the PI variable.

Additionally, Keith et al. [11] found unique variance attributable to ethnicity. The authors coded ethnicity as 1 for White and Asian and 0 for Black, Hispanic, and Native American. While White and Asian students showed generally higher achievement than Black, Hispanic, and Native American students, what is interesting is that parents of Ethnicity 0 reported more PI than parents of Ethnicity 1 (shown by the inverse relation between ethnicity and PI). Finally, the data for family socioeconomic status (SES, reflected by the family background variable) showed that higher SES was associated with higher student achievement.

Our fifth large-scale study, conducted by Chen [8], was similarly a structural analysis investigating students in different grade levels (i.e., grades 9 to 11) in terms of their perceived academic involvement from their parents. This 


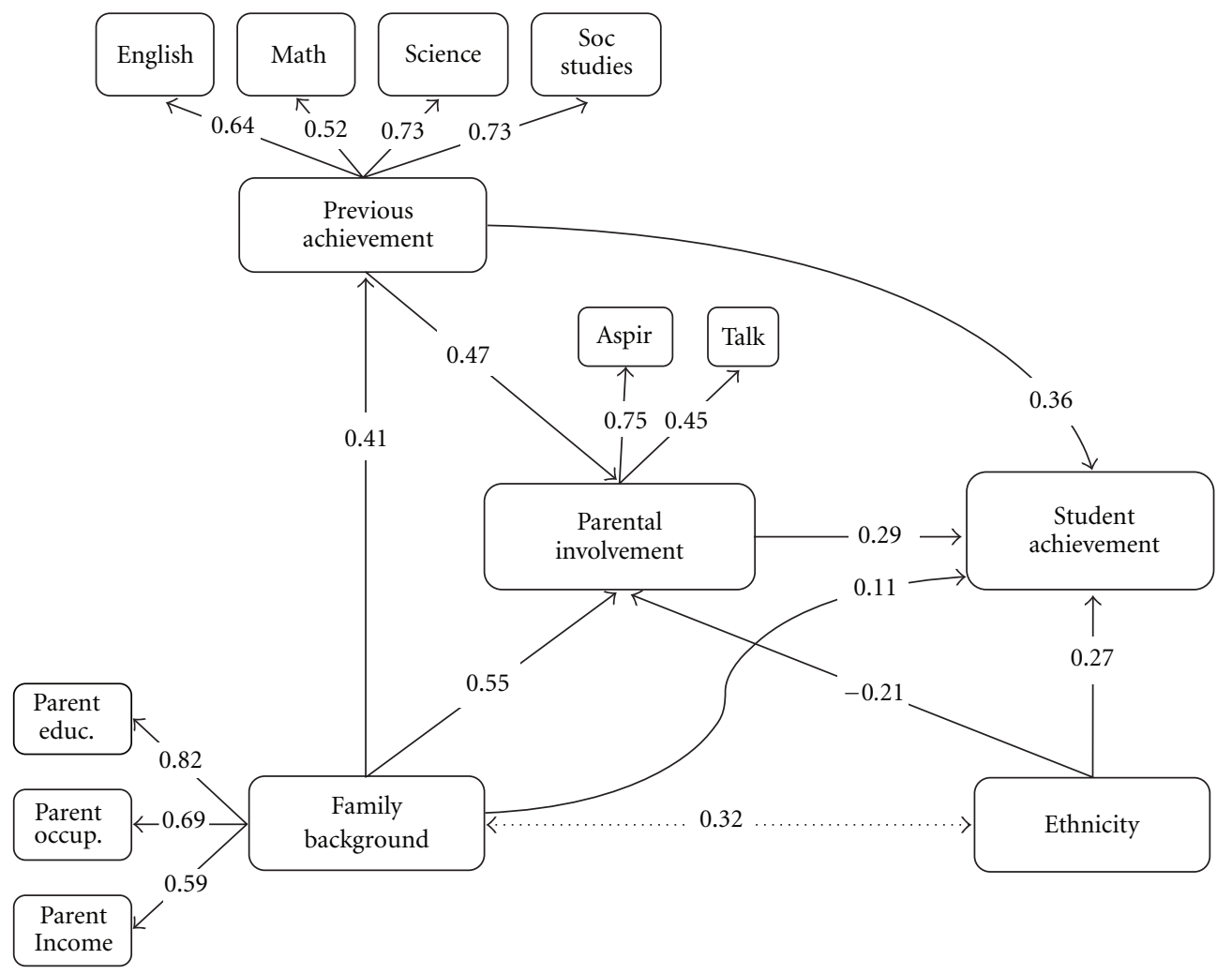

Figure 4: Keith et al.'s [11] structural equation model of parental involvement variables and student achievement. Note: from "Does parental involvement affect eighth-grade student achievement? Structural analysis of national data,” by T. Z. Keith, P. B. Keith, G. C. Troutman, P. G. Bickley, P. S. Trivette, and K. Singh, 1993, School Psychology Review, 22(3), p. 488.

involvement was then examined relative to academic achievement directly and also indirectly through students' selfreported academic engagement such as study time (which included hours that students reported doing their homework), studying during a typical week, and motivation to go to school.

Data were collected through questionnaires administered to 270 Hong Kong students in the three grade levels. Structural equation modeling (SEM) analysis revealed interesting findings regarding parental support. The first finding showed that the indirect relationship of the students' perceived PI to academic achievement was mediated by perceived academic engagement. This finding, however, was significant only for 9 th grade students $(P<.05)$. The second finding revealed that perceived PI was directly and negatively related to academic achievement for all grade levels but statistically significant only for the 10th grade students. In short, (a) perceived PI appears to predict academic achievement, and (b) higher levels of perceived PI are associated with lower levels of achievement, especially for 10th graders in Hong Kong.

In our final large-scale study, Sui-Chu and Willms [2] computed regression and factor analyses to predict mathematics achievement using PI factors (i.e., home discussion, home supervision, school communication, and school participation), family variables (i.e., SES, number of siblings, number of parents, learning problem, and behavioral problem), and ethnicity (i.e., White, Asian or Pacific Islander,
Hispanic, Black, or Native American) using NELS: 88 data for mathematics.

All of the variables were significant at the $P<.01$ level except for the nonsignificant effects of (a) number of parents in the home, and (b) home supervision (e.g., rules), both of which may be contrary to conventional wisdom (i.e., the deleterious effects of single-parent homes on achievement, and the importance of rules). Of the PI factors, the largest predictor of mathematics achievement is again the degree to which parents and their children talk about school (i.e., home discussion). Finally, Sui-Chu and Willms [2] reported that PI made a significant unique contribution to explaining variation in students' academic achievement, over and above the effects associated with parental background.

4.9. Limitations of Nonexperimental Research. After reviewing the PI literature, it is worth noting some of the main limitations of PI research in conjunction with their possible ramifications. These include the following.

(i) Use of nonexperimental design leads to the inability to distinguish between correlation and causation.

(ii) Inconsistent definitions of PI leads to difficulty in comparing/interpreting findings across studies that define this construct differently. 


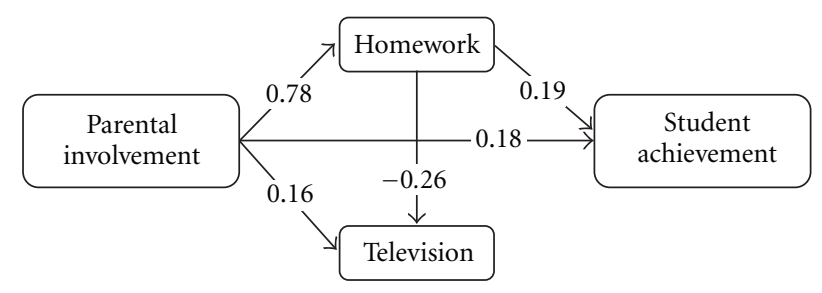

FIGURE 5: Relationship between PI and achievement with homework and television viewing as mediating variables. Note: adapted from "Does parental involvement affect eighth-grade student achievement? Structural analysis of national data," by T. Z. Keith, P. B. Keith, G. C. Troutman, P. G. Bickley, P. S. Trivette, and K. Singh, 1993, School Psychology Review, 22(3), p. 490.

(iii) Lack of isolation of PI effects leads to the inability to distinguish effects due to PI from genetic and other environmental variables.

One observation from reviewing this literature concerns the need to be cautious about interpreting correlational data. For instance, we saw earlier that the variable parents checking homework is often negatively associated with student academic achievement. This is likely because parents tend to check homework more vigilantly when there are academic problems, making PI in the form of homework checking an effect rather than a cause of academic achievement. Further, actually doing homework (by the child) has been shown to be positively associated with academic achievement [11].

In addition, there may be other mediating factors relating to PI effects on student achievement that have not yet been adequately researched. For example, as part of their research and analysis using structural modeling, Keith et al. [11] examined mediating variables involving PI and academic achievement. As shown in Figure 5, PI is characterized as exerting its effect on student achievement via the mediating variable of homework, where more PI is associated with doing more homework, which in turn is associated with higher achievement. Also, according to this model, doing more homework is associated with less TV viewing.

The literature we reviewed has paid little attention to possible interactions among classes of important variables. In short, caution is warranted in attributing direct effects of parenting, genes, or social/environmental factors because all three may interact with each other in predicting academic achievement.

4.10. Children's versus Parents' Perspectives. As noted earlier, the literature shows that children's perceptions about PI variables appear to be better predictors of student achievement than parents' perceptions $[8,9,42]$. In addition, most of the studies show that PI and its probable influence on achievement declines as children progress through school $[5,40]$. There are several possible reasons for this decline: (a) middle and high schools become more complex, with more demanding curricula that can intimidate parents; (b) there are fewer school outreach efforts to involve parents in the secondary school years; (c) parents may exert progressively less influence over their adolescent children as they become more independent $[8,37,43,44]$. Regarding the latter point, as students become older, they start to rely on peers for advice and support more than on their parents. Peer group influences have a powerful effect on children's motivation to do well in school $[45,46]$.

The fields of education and psychology appear to be adjusting to the challenge directed toward the more traditional view that parenting has a very large influence on children's development. What the emerging view will be remains to be seen. One possible view might be similar to the view expressed by Cohen [47], who argued that while both parent and peer influences are modest, the peer influence is smaller and parent influence is larger than estimated by Harris, who asserted that differences in parenting have essentially no lasting influence on how children turn out [44].

Despite the relative modesty of the influence of PI in the research cited in this paper, there is a need for caution in underemphasizing the importance of parents' efforts on behalf of their children, academically and otherwise. Even Harris [44] warns that her theory (which does not attribute lasting parental influence) is not intended to imply that children can get along without their parents. In fact, "children are emotionally attached to their parents (and vice versa), are dependent on them for protection and care, and learn skills within home that may prove useful outside it; these facts are not questioned" [48, p. 461].

Thus, Harris affirmed the key role of parents in protection, care, and support of learning. Furthermore, given that parents play a key role in selecting or otherwise determining a child's home, school, neighborhood, and cultural group, we can see that parents have an importance that may not be fully captured in these studies. And, as Levitt and Dubner [49] have noted, "Clearly, bad parenting matters a great deal...[U]nwanted children-who are disproportionately subject to neglect and abuse-have worse outcomes than children who are eagerly welcomed by their parents" (pp. 153-154).

\section{Conclusions}

Parents appear to have an important opportunity to influence their children's academic achievement though the influence may not be as great as traditionally believed. Correlational studies have found modest associations between various PI variables and student academic achievement, with some of the most consistent relationships being reported for (a) parents talking with their child about school [2, 4, 8$11,50]$, (b) parents holding high expectations for students' 
academic achievement $[1,3,10,14]$, and (c) parents employing an authoritative (not authoritarian) parenting style [10, $17,19,20]$. Citing the inability of correlational studies to determine causality, as well as the findings of twin and adoption studies, researchers have estimated the impact of PI variables on academic achievement as quite modest [44, 4749]. Others have agreed that the influence of parents is modest but go on to assert that peer influence is likewise modest [47]. It seems that both parents and peers can have an influence on a child's academic achievement.

Given that parents have limited influence over the child's peer relationships, direct parental influence remains an opportunity to leverage those factors for the benefit of the child, including their academic achievement. The design of policies, practices, and interventions should reflect an understanding of these findings about the nature and magnitude of parental influence on children's academic achievement.

\section{References}

[1] A. J. L. Baker and L. M. Soden, "ED419030 1998-04-00 the challenges of parent involvement research," Tech. Rep. ERIC/CUE Digest Number 134, ERIC Clearinghouse on Urban Education, New York, NY, USA, 1998.

[2] E. H. Sui-Chu and J. D. Willms, "Effects of parental involvement on eighth-grade achievement," Sociology of Education, vol. 69, no. 2, pp. 126-141, 1996.

[3] H-F. Chen, The longitudinal factor structure of parent involvement and its impact on academic achievement: findings from the ECLS-K dataset, ProQuest Dissertations, University of Denver, Denver, Colo, USA, 2009.

[4] R. B. McNeal, "Parental involvement as social capital: differential effectiveness on science achievement, truancy, and dropping out," Social Forces, vol. 78, no. 1, pp. 117-144, 1999.

[5] E. N. Patrikakou, "Adolescence: are parents relevant to high school students' achievement," FINE network at Harvard Family Research Project, 2004, http://www.gse.harvard .edu/hfrp/projects/fine/resources/digest/adolescence.html.

[6] Institute of Education Sciences. (n.d.), "National Longitudinal Study of 1988," National Center for Educational Statistics Web site, http://nces.ed.gov/surveys/nels88/.

[7] S. Catsambis, "Expanding knowledge of parental involvement in secondary education: effects on high school academic success," Tech. Rep. 27, Johns Hopkins University, Center for Research on the Education of Students Placed at Risk, Baltimore, Md, USA, 1998.

[8] J. J. L. Chen, "Grade-level differences: relations of parental, teacher and peer support to academic engagement and achievement among Hong Kong students," School Psychology International, vol. 29, no. 2, pp. 183-198, 2008.

[9] L. Desimone, "Linking parent involvement with student achievement: do race and income matter?" Journal of Educational Research, vol. 93, no. 1, pp. 11-30, 1999.

[10] W. H. Jeynes, "The relationship between parental involvement and urban secondary school student academic achievement: a meta-analysis," Urban Education, vol. 42, no. 1, pp. 82-110, 2007.

[11] T. Z. Keith, P. B. Keith, G. C. Troutman, P. G. Bickley, P. S. Trivette, and K. Singh, "Does parental involvement affect eighthgrade student achievement? Structural analysis of national data," School Psychology Review, vol. 22, no. 3, pp. 474-496, 1993.
[12] J. Battle, "Longitudinal analysis of academic achievement among a nationwide sample of Hispanic students in oneversus dual-parent households," Hispanic Journal of Behavioral Sciences, vol. 24, no. 4, pp. 430-447, 2002.

[13] E. Dearing, K. McCartney, H. B. Weiss, H. Kreider, and S. Simpkins, "The promotive effects of family educational involvement for low-income children's literacy," Journal of School Psychology, vol. 42, no. 6, pp. 445-460, 2004.

[14] X. Fan and M. Chen, "Parental involvement and students' academic achievement: a meta-analysis," Educational Psychology Review, vol. 13, no. 1, pp. 1-22, 2001.

[15] K. Singh, P. G. Bickley, P. S. Trivette, T. Z. Keith, P. B. Keith, and E. S. Anderson, "The effects of four components of parental involvement on eighth grade student achievement: Structural analysis of NELS-88 data," School Psychology Review, vol. 24, pp. 299-317, 1995.

[16] L. A. Kurdek, M. A. Fine, and R. J. Sinclair, "School adjustment in sixth graders: parenting transitions, family climate, and peer norm effects," Child Development, vol. 66, no. 2, pp. 430-445, 1995.

[17] D. Baumrind, "Current patterns of parental authority," Developmental Psychology, vol. 4, no. 1, pp. 1-103, 1971.

[18] E. E. Maccoby, "Parenting and its effects on children: on reading and misreading behavior genetics," Annual Review of Psychology, vol. 51, pp. 1-27, 2000.

[19] E. E. Maccoby and J. A. Martin, "Socialization in the context of the family: parent-child interaction," in Handbook of Child Psychology, Socialization, Personality and Social Development, P. H. Mussen and E. M. Hetherington, Eds., vol. 4, pp. 1-101, John Wiley \& Sons, New York, NY, USA, 4th edition, 1983.

[20] S. E. Paulson, "Relations of parenting style and parental involvement with ninth-grade students' achievement," Journal of Early Adolescence, vol. 14, no. 2, pp. 250-267, 1994.

[21] D. Baumrind, "Parental disciplinary patterns and social competence in children," Youth \& Society, vol. 9, no. 3, pp. 239251, 1978.

[22] D. H. Demo and M. J. Cox, "Families with young children: a review of research in the 1990s," Journal of Marriage and Family, vol. 62, no. 4, pp. 876-895, 2000.

[23] S. M. Dornbusch, P. L. Ritter, P. H. Leiderman, D. F. Roberts, and M. J. Fraleigh, "The relation of parenting style to adolescent school performance," Child Development, vol. 58, no. 5, pp. 1244-1257, 1987.

[24] B. Radziszewska, J. L. Richardson, C. W. Dent, and B. R. Flay, "Parenting style and adolescent depressive symptoms, smoking, and academic achievement: ethnic, gender, and SES differences," Journal of Behavioral Medicine, vol. 19, no. 3, pp. 289-305, 1996.

[25] D. A. Adeyemo, "Parental involvement, interest in schooling and school environment as predictors of academic self-efficacy among fresh secondary school students in Oyo State, Nigeria," Electronic Journal of Research in Educational Psychology, vol. 3, no. 1, pp. 163-180, 2005.

[26] K. Aunola, H. Stattin, and J. -E. Nurmi, "Parenting styles and adolescents' achievement strategies," Journal of Adolescence, vol. 23, no. 2, pp. 205-222, 2000.

[27] R. Deslandes, P. Bouchard, and J.-C. St-Amant, "Family variables as predictors of school achievement: sex differences in Quebec adolescents," Canadian Journal of Education, vol. 23, no. 4, pp. 390-404, 1998.

[28] R. Deslandes, E. Royer, D. Turcotte, and R. Bertrand, "School achievement at the secondary level: influence of parenting style and parent involvement in schooling," McGill Journal of Education, vol. 32, pp. 191-208, 1997. 
[29] S. D. Lamborn, N. S. Mounts, L. Steinberg, and S. M. Dornbusch, "Patterns of competence and adjustment among adolescents from authoritative, authoritarian, indulgent, and neglectful families," Child Development, vol. 62, no. 5, pp. 1049-1065, 1991.

[30] G. J. Marchant, S. E. Paulson, and B. A. Rothlisberg, "Relations of middle school students' perceptions of family and school contexts with academic achievement," Psychology in the Schools, vol. 38, no. 6, pp. 505-519, 2001.

[31] R. K. Chao, "Extending research on the consequences of parenting style for Chinese Americans and European Americans," Child Development, vol. 72, no. 6, pp. 1832-1843, 2001.

[32] D. Miliotis, A. Sesma Jr., and A. S. Masten, "Parenting as a protective process for school success in children from homeless families," Early Education \& Development, vol. 10, no. 2, pp. 111-133, 1999.

[33] K. Kim and R. P. Rohner, "Parental warmth, control, and involvement in schooling: predicting academic achievement among Korean American adolescents," Journal of CrossCultural Psychology, vol. 33, no. 2, pp. 127-140, 2002.

[34] J. Tizard, W. Schofield, and J. Hewison, "Collaboration between teachers and parents in assisting children's reading," British Journal of Educational Psychology, vol. 52, pp. 1-15, 1994.

[35] R. Clark, "Homework-focused parenting practices that positively affect student achievement," in Families and Schools in a Pluralistic Society, N. F. Chavkin, Ed., pp. 85-105, State University of New York, New York, NY, USA, 1993.

[36] C. Snow, W. Barnes, J. Chandler, I. Goodman, and L. Hemphill, Unfulfilled Expectations: Home and School Influences on Literacy, Harvard University Press, Cambridge, Mass, USA, 1991.

[37] E. H. De Bruyn, "Role strain, engagement and academic achievement in early adolescence," Educational Studies, vol. 31, no. 1, pp. 15-27, 2005.

[38] V. Lee and R. Croninger, "The relative importance of home and school in the development of literacy skills for middlegrade students," American Journal of Education, vol. 102, no. 3, pp. 286-329, 1994.

[39] A. Milne, "Family structure and the achievement of children," in Education and the American Family, W. Wiston, Ed., SUNY University Press, New York, NY, USA, 1989.

[40] N. Zill and C. W. Nord, Running in Place: How American Families Are Faring in a Changing Economy and an Individualistic Society, Child Trends, Washington, DC, USA, 1994.

[41] J. Cohen, Statistical Power Analysis for the Behavioral Sciences, Lawrence Erlbaum, Hillsdale, NJ, USA, 2nd edition, 1988.

[42] R. B. McCall, S. R. Beach, and S. Lau, "The nature and correlates of underachievement among elementary schoolchildren in Hong Kong," Child Development, vol. 71, no. 3, pp. 785$801,2000$.

[43] M. Azmitia and C. R. Cooper, "Good or bad? Peer influences on Latino and European American adolescents' pathways through school," Journal of Education for Students Placed at Risk, vol. 6, no. 1-2, pp. 45-71, 2001.

[44] J. R. Harris, The Nurture Assumption: Why Children Turn out the Way They Do, Simon \& Schuster, New York, NY, USA, 1998.

[45] A. J. Fuligni, J. S. Eccles, B. L. Barber, and P. Clements, "Early adolescent peer orientation and adjustment during high school," Developmental Psychology, vol. 37, no. 1, pp. 2836, 2001.

[46] T. A. Kindermann, "Natural peer groups as contexts for individual development: the case of children's motivation in school," Developmental Psychology, vol. 29, no. 6, pp. 970-977, 1993.

[47] D. B. Cohen, Stranger in the Nest: Do Parents Really Shape Their Child's Personality, Intelligence, or Character? John Wiley \& Sons, New York, NY, USA, 1999.

[48] J. R. Harris, "Where is the child's environment? A group socialization theory of development," Psychological Review, vol. 102, no. 3, pp. 458-489, 1995.

[49] S. D. Levitt and S. J. Dubner, Freakonomics: A Rogue Economist Explores the Hidden Side of Everything, William Morrow, New York, NY, USA, 2005.

[50] A. T. Henderson and K. L. Mapp, A New Wave of Evidence: The Impact of School, Family, and Community Connections on Student Achievement, Southwest Educational Development Laboratory, Austin, Tex, USA, 2002. 


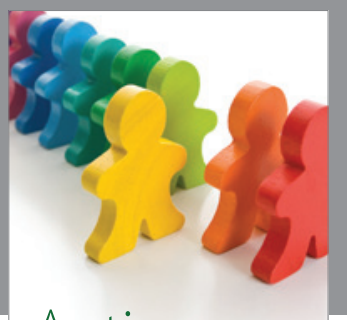

Autism

Research and Treatment
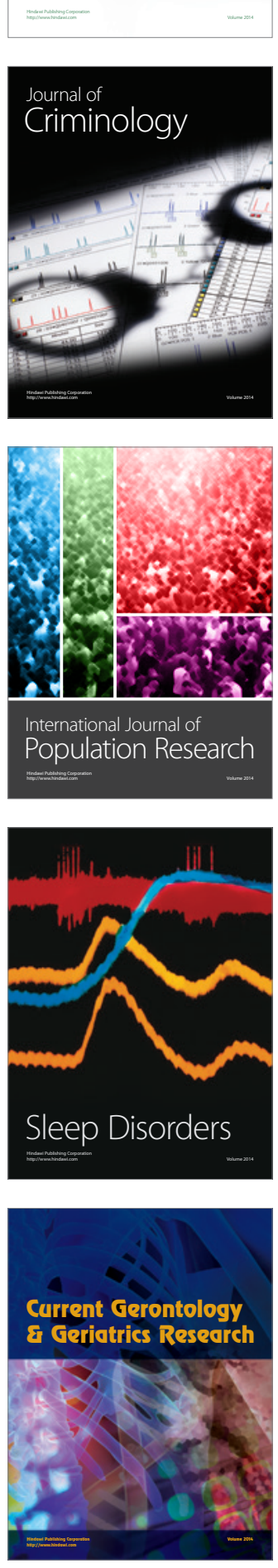
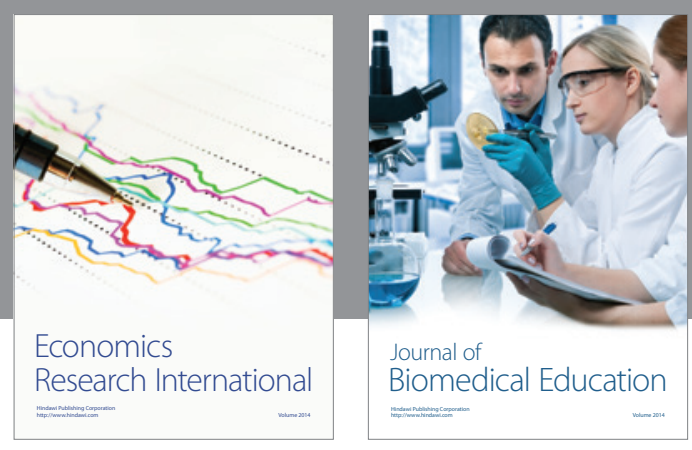

Journal of

Biomedical Education

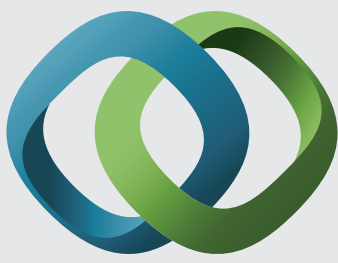

\section{Hindawi}

Submit your manuscripts at

http://www.hindawi.com
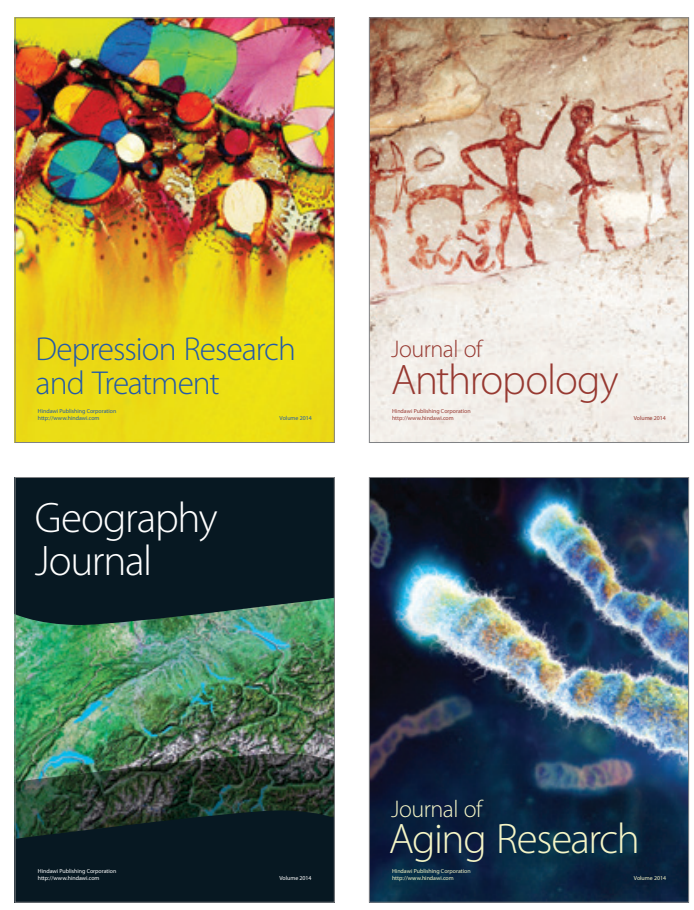

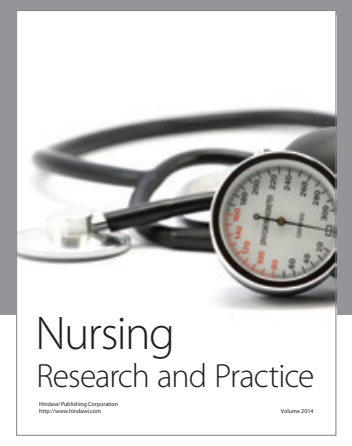

Nursing

Research and Practice

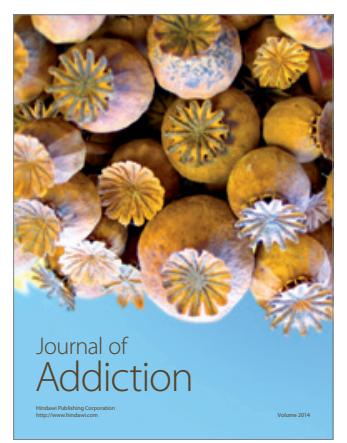

Child Development

Research

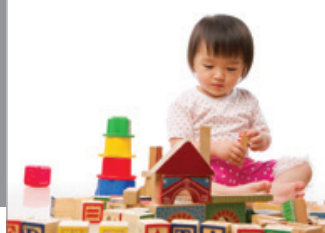

迥
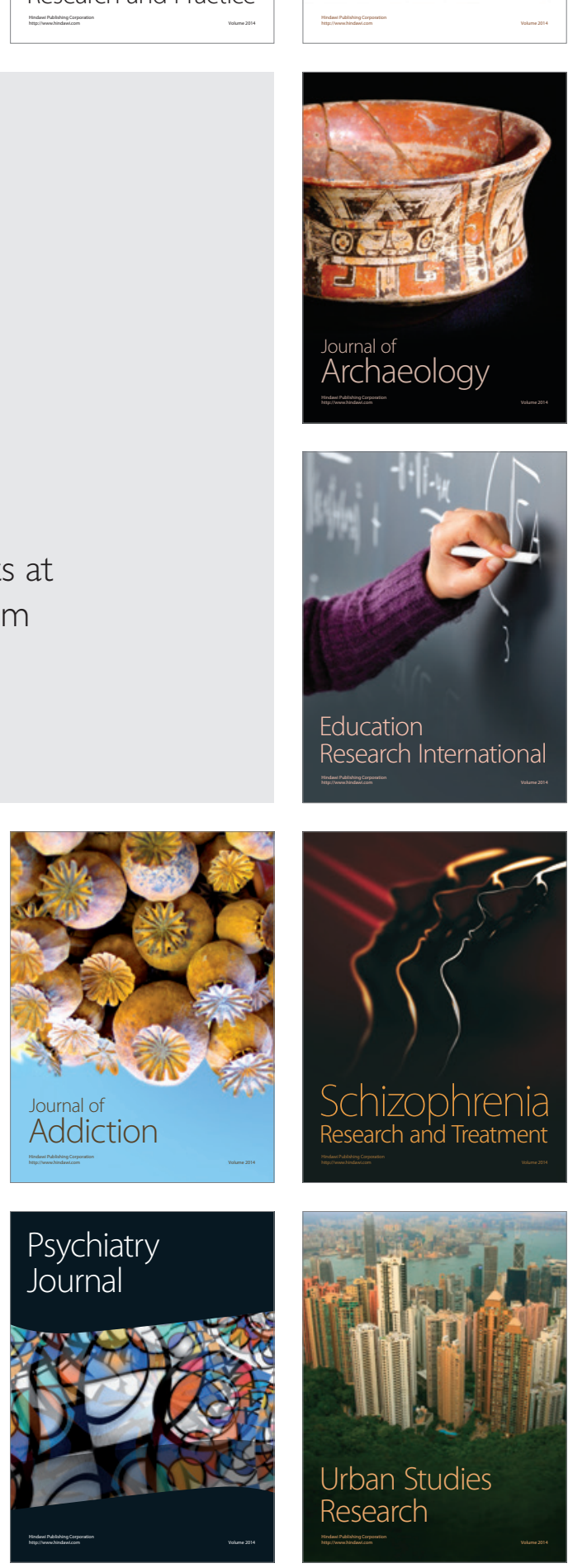